\title{
Um Estudo Exploratório sobre as Atitudes em Relação aos Conhecimentos Matemáticos de Professoras da Educação Infantil
}

\section{An Exploratory Study on the Attitudes towards Mathematical Knowledge of Early Childhood Education Teachers}

\author{
iD Evandro Tortora' ${ }^{1}$ \\ Delson Antonio Pirola² \\ 'Secretaria Municipal de Educação, Campinas, SP, Brasil. \\ Autor Correspondente: evandro_tta@hotmail.com \\ ${ }^{2}$ Universidade Estadual Paulista (UNESP), Faculdade de Ciências, Departamento de Educação, Bauru, SP, Brasil.
}

Resumo: Este artigo tem por objetivo apresentar os resultados de uma investigação sobre as atitudes de professoras da Educação Infantil frente aos conhecimentos matemáticos em suas práticas com as crianças. Participaram deste estudo 115 professoras de Educação Infantil que responderam a uma escala de atitudes em relação ao trabalho com conhecimentos matemáticos na Educação Infantil e, deste grupo, 55 professoras que responderam a um questionário. As análises dos dados mostraram que a maioria das professoras que respondeu à escala de atitudes tende a ser mais negativa; porém as análises qualitativas dos questionários revelaram atitudes mais positivas, bem como apontaram que as experiências positivas em relação à matemática tiveram maior influência na formação das atitudes das professoras e as experiências negativas serviram como exemplos de práticas a serem superadas em sua atividade docente.

Palavras-chave: Educação infantil; Educação matemática; Comportamento do professor; Atitude do professor.

Abstract: This article aims to present the results of an investigation on the attitudes of early childhood education teachers towards working with mathematical knowledge. In this study, 115 kindergarten teachers participated, who responded to a scale of attitudes towards working with mathematical knowledge in kindergarten. In this group, 55 teachers responded to a questionnaire. The analysis of the data showed that the majority of the teachers who answered the scale of attitudes tend to have more negative attitudes; however, the qualitative analysis of the questionnaires revealed more positive attitudes. In addition, it pointed out that the positive experiences in relation to mathematics had greater influence on the formation of the teachers' attitudes, whereas the negative experiences served as examples of practices to be put aside in their teaching activities.

Keywords: Early childhood Education; Mathematics education; Teachers' behavior; Teachers' attitudes.

Recebido em: 30/05/2020

Aprovado em: 25/10/2020 


\section{Conhecimentos Matemáticos e Educação Infantil}

Ao longo do tempo, vários documentos oficiais foram elaborados a fim de tornar a Educação Infantil um espaço de aprendizagem como direito da criança. As Diretrizes Curriculares Nacionais para a Educação Infantil (DCNEI) trazem várias contribuições nesse sentido, ressaltando, inclusive, que as experiências pedagógicas na Educação Infantil devem garantir experiências que recriem "[...] em contextos significativos para as crianças, relações quantitativas, medidas, formas e orientações espaço temporais" (BRASIL, 2010, p. 25).

Na mesma perspectiva, a Base Nacional Comum Curricular (BNCC) coloca as experiências das crianças na Educação Infantil como elemento chave para aprendizagem quando destaca que "[...] as creches e pré-escolas têm o objetivo de ampliar o universo de experiências, conhecimentos e habilidades dessas crianças, diversificando e consolidando novas aprendizagens, atuando de maneira complementar à educação familiar" (BRASIL, 2018, p. 34).

O cotidiano da Educação Infantil ganha destaque nesse tipo de concepção visto que "[...] a interação durante o brincar caracteriza o cotidiano da infância, trazendo consigo muitas aprendizagens e potenciais para o desenvolvimento integral das crianças" (BRASIL, 2018, p. 35).

Tanto a BNCC quanto a DCNEI destacam a importância da intencionalidade pedagógica da Educação Infantil, porém ainda é necessário destacar a relevância dos conhecimentos produzidos e sistematizados da matemática, conforme Wiggers (2012, p. 112) salienta:

\footnotetext{
Para o delineamento dos diferentes níveis de planejamento se faz necessário considerar diversos aspectos, tais como: indicações legais, orientações oficiais e os conhecimentos produzidos e sistematizados pelas diferentes áreas do conhecimento. A partir dessas indicações evidencia-se que o planejamento na creche e na pré-escola precisa ser compreendido numa perspectiva ampla, o qual inclui a sistematização do currículo, proposta pedagógica como eixo norteador do trabalho cotidiano em qualquer estabelecimento de ensino.
}

Muitos fatores podem ter influências nos caminhos tomados pelo professor durante o planejamento de práticas pedagógicas que envolvam o ensino da matemática na Educação Infantil, dentre eles, as suas atitudes em relação à matemática.

\section{As Atitudes em relação à Matemática e à Docência na Educação Infantil}

Associado a compreensões do senso comum, o termo atitude pode gerar entendimentos equivocados e divergentes em seu uso no âmbito acadêmico. Brito (1996), umas das principais pesquisadoras sobre a temática das atitudes, orientou trabalhos como o de Gonçalez (2000) e Moron (1998), os quais concordam que as atitudes estão relacionadas à ideia de uma "[...] predisposição, aceitação ou rejeição, favorável ou desfavorável, positiva ou negativa, aproximativa ou esquiva" (GONÇALEZ, 2000, p. 33).

Brito (1996) apresenta a seguinte definição para a palavra atitude: 
Atitude poderia ser definida como uma disposição pessoal, idiossincrática, presente em todos os indivíduos, dirigida a objetos, eventos ou pessoas, que assume diferente direção e intensidade de acordo com as experiências do indivíduo. Atitude é sempre 'atitude com relação a', isso é, atitude sempre possui um referente. Quando falamos de atitude, estamos nos referindo a um evento interno, apreendido, com componentes cognitivos e afetivos, que varia em intensidade e é dirigido a um determinado objeto (BRITO, 1996, p. 11).

Tal definição nos ajuda a compreender a forma como os indivíduos se relacionam com a matemática enquanto objeto de conhecimento, quando analisamos suas atitudes em relação à matemática. Esses indivíduos revelam atitudes que acabam tendendo a ser mais positivas ou mais negativas, dependendo das suas experiências com o objeto.

Com relação aos aspectos pedagógicos, Klausmeier (1977) ressalta que as atitudes podem ser ensinadas. Corroborando a afirmação deste autor, Brito (1996) e De Corte (1995) apontam a relevância da figura do professor como alguém que influencia no desenvolvimento de crenças e de atitudes nos estudantes. Caso o professor tenha atitudes positivas em relação aos conhecimentos matemáticos, as mesmas poderão ser ensinadas às crianças.

Existe certa preocupação com relação às vivências passadas dos docentes, que podem colaborar para a construção de atitudes negativas. Brito (1996) explica que as mudanças dessas atitudes devem ser conseguidas em longo prazo:

[...] certas tentativas de mudança, na prática, limitam-se a ações episódicas que se concentram em incluir ou excluir disciplinas, aumentar ou diminuir a carga horária, como se isso fosse suficiente para alterar todos os demais componentes do processo de formação de professores. É esquecido que isso envolve uma mudança de atitudes dos indivíduos com relação ao ensino e à formação de professores (sua relevância e importância) e elas não ocorrem a curto prazo (BRITO, 1996, p. 15).

Trata-se de proporcionar mudanças na formação de professores, que considerem as características transversais ao currículo universitário. Envolve, além de revisão dos programas de disciplinas, uma mudança de postura perante a matemática e suas práticas dentro do curso de Pedagogia e na sala de aula.

Com relação à Educação Infantil, Moron (1998) desenvolveu uma das primeiras pesquisas que investigou as atitudes de docentes em relação à matemática, bem como a influência destes no trabalho com as crianças. A autora afirma que docentes da Educação Infantil sofrem influência de suas crenças e concepções.

Acreditamos que os professores que ensinam matemática na educação infantil formam idéias sobre a natureza da matemática e do seu ensino a partir de experiências que tiveram como alunos e professores, das atitudes que formaram, do conhecimento que construíram, das opiniões dos mestres, enfim, das influências socioculturais que sofreram durante sua trajetória, influências essas que vão se formando ao longo de sua vida (MORON, 1998, p. 25).

Logo, é relevante que esses professores e professoras tenham atitudes positivas em relação à matemática, uma vez que, como afirmam Moraes e Pirola (2015, p. 62), "[...] o professor deveria auxiliar os seus alunos a terem boas experiências com a Matemática escolar, o que contribuiria para construir atitudes positivas em relação a essa disciplina". 
Alguns professores podem apresentar dificuldades em planejar atividades que envolvam conhecimentos matemáticos, o que pode surtir efeitos na aprendizagem das crianças e no desenvolvimento de suas atitudes. Sobre esse cenário, Brito (1996, p. 146) salienta que "[...] para desenvolver atividades docentes adequadas, o indivíduo necessita apresentar atitudes positivas com relação ao ensino, à disciplina que vai ensinar aos alunos e à própria escola".

Nesse sentido, este artigo apresenta os resultados de uma pesquisa sobre as atitudes de professoras ${ }^{1}$ de Educação Infantil.

\section{Caracterização do Método de Estudo}

Este artigo é derivado de uma tese de doutorado (TORTORA, 2019) e tem como objetivo apresentar os resultados de uma investigação sobre as atitudes de professoras da Educação Infantil frente aos conhecimentos matemáticos em suas práticas com as crianças.

A pesquisa foi desenvolvida em duas etapas, sendo a primeira de cunho quantitativo, e a segunda, de caráter qualitativo. Ferreira (2015) reforça a condição complementar entre esses dois métodos quando afirma que:

$\mathrm{Na}$ verdade, as duas abordagens de pesquisa - qualitativa e quantitativa - são convergentes em muitas pesquisas científicas realizadas, sendo o contexto o elemento definidor de qual caminho seguir, ou seja, em qual dos aspectos será colocada uma ênfase maior (FERREIRA, 2015, p. 118).

Cabe destacar que ambos os métodos contribuíram complementarmente para esta investigação. Neste artigo são apresentados os resultados obtidos por meio de uma escala de atitudes (instrumento que teve análise quantitativa) e um questionário (no qual se fez uso de uma análise qualitativa).

\section{A Escala de Atitudes}

A escala de atitudes foi adaptada e validada a partir dos estudos de Moron (1998). A pesquisadora já havia validado uma escala de atitudes em relação à matemática para professores de Educação Infantil, porém, este instrumento precisou passar por uma revisão e algumas terminologias precisaram ser substituídas. Por conta das adaptações nos itens da escala, o instrumento precisou ser novamente validado.

A escala manteve a mesma quantidade de itens da escala utilizada por Moron (1998), possuindo um total de 21 itens, sendo 10 afirmações positivas, 10 negativas e uma afirmação relacionada com a autoeficácia. No quadro 1 seguem alguns exemplos de itens da escala utilizada na pesquisa.

\footnotetext{
${ }^{1}$ Nenhum participante se identificou como sendo do gênero masculino; sendo assim, ao referir-se ao grupo de
} docentes, será utilizada a palavra professora. 
Quadro 1 - Exemplos de questões da escala de atitudes em relação à matemática

\begin{tabular}{|l|l|}
\hline \multicolumn{1}{|c|}{ Exemplos de afirmações positivas } & \multicolumn{1}{c|}{ Exemplos de afirmações negativas } \\
\hline $\begin{array}{l}\text { Eu acho a matemática muito interessante e gosto de trabalhar } \\
\text { conhecimentos da matemática com as crianças. }\end{array}$ & $\begin{array}{l}\text { Eu fico sempre sob uma terrível tensão ao trabalhar com } \\
\text { conhecimentos de matemática com as crianças. }\end{array}$ \\
\hline A matemática é fascinante e divertida. & $\begin{array}{l}\text { A matemática me deixa inquieto (a), descontente, irritado } \\
\text { (a) e impaciente. }\end{array}$ \\
\hline A matemática é algo que eu aprecio grandemente. & $\begin{array}{l}\text { Quando eu ouço a palavra matemática, eu tenho um } \\
\text { sentimento de aversão. }\end{array}$ \\
\hline
\end{tabular}

Fonte: Tortora (2019).

A escala de atitudes é do tipo Likert, na qual ocorre a soma da pontuação obtida em cada uma das questões para averiguar o resultado total da pontuação na escala. A pontuação de cada item pode variar de 1 a 4, sendo que as opções de resposta aos itens são concordo totalmente, concordo, discordo e discordo totalmente, seguindo a seguinte lógica:

Quadro 2 - Pontuações na escala de atitudes

\begin{tabular}{|l|c|c|}
\hline Valor da alternativa & Afirmação positiva & Afirmativa negativa \\
\hline Concordo totalmente & 4 & 1 \\
\hline Concordo & 3 & 2 \\
\hline Discordo & 2 & 3 \\
\hline Discordo totalmente & 1 & 4 \\
\hline
\end{tabular}

Fonte: Tortora (2019).

Uma vez que a escala foi respondida, somam-se os resultados de todos os participantes e calcula-se a média de suas respostas. Esta média serve como parâmetro para classificar cada participante da pesquisa com relação à sua tendência em apresentar atitudes positivas ou negativas em relação à matemática. As professoras que tiveram uma pontuação acima da média são consideradas participantes que tendem a ter atitudes positivas em relação à matemática. No caso das professoras com pontuação abaixo da média, são consideradas como aquelas que tendem a ter atitudes negativas em relação à matemática.

Trata-se de um procedimento elaborado e utilizado, primeiramente, em uma escala de atitudes em relação à matemática elaborada por Aiken Jr. e Dreger (1961). Brito (1996) foi responsável por fazer a adaptação e validação desta escala para o contexto brasileiro. Desde então, outros estudos têm utilizado o mesmo instrumento (ou adaptações), seguindo o mesmo critério de análise para as pontuações (COUTINHO, 2020; JUSTULIN, 2009; MORON, 1998; SANDER, 2014; SANTANA, 2019; VENDRAMINI, 2000).

Após a escrita da escala, foi necessário verificar sua validade e seu grau de confiabilidade, por meio de análises estatísticas. A validade da escala diz respeito à adequação do instrumento para se medir o que se espera; para tanto, o instrumento foi submetido à Análise Fatorial. Por meio da referida análise, foi possível constatar a estrutura unidimensional deste instrumento, a partir da qual se afere as atitudes a partir da soma dos valores dos seus itens.

A confiabilidade da escala de atitudes foi verificada por meio do cálculo do coeficiente alfa de Cronbach, o qual se configura como uma maneira de estudar a confiabilidade de instrumento, dependendo de sua finalidade na pesquisa. 
O coeficiente alfa de Cronbach viabiliza a medição da correlação entre os itens de um instrumento, por meio da análise estatística das respostas dadas pelos participantes, que pode ser averiguada através de um valor que pode variar de 0 a 1.

Freitas e Rodrigues (2005) afirmam que não existe consenso entre os pesquisadores sobre a interpretação dos valores de alfa para análise de confiabilidade de escalas; contudo os autores fazem a indicação de classificação de valores mostrada na Tabela 1.

Tabela 1 - Classificação da confiabilidade a partir do coeficiente a de Cronbach

\begin{tabular}{lccccc}
\hline Confiabilidade & Muito Baixa & Baixa & Moderada & Alta & Muito alta \\
\hline Valor de $\boldsymbol{a}$ & $a \leq 30$ & $0,30<a \leq 0,60$ & $0,60<a \leq 0,75$ & $0,75<a \leq 0,90$ & $a>0,90$ \\
\hline & Fonte: Freitas e Rodrigues (2005). &
\end{tabular}

Para auxiliar nas análises deste trabalho, o alfa de Cronbach foi calculado com a ajuda do software Statistical Package for Social Sciences (SPSS) ${ }^{2}$. O alfa de Cronbach obtido para a escala de atitudes foi de 0,943, ou seja, considerando os parâmetros de Freitas e Rodrigues (2005), a escala apresenta alta confiabilidade. Para maior detalhamento do processo de validação e verificação do grau de confiabilidade da escala recomenda-se a consulta a Tortora (2019).

\section{O Questionário}

Em complemento à escala de atitudes, foi elaborado um questionário com perguntas abertas sobre os sentimentos das professoras em relação à matemática e à docência. Esse instrumento passou por um pré-teste e foi revisado até chegar à sua versão final.

Foi solicitado que todas as professoras que responderam à escala também respondessem ao questionário: do total de 115 professoras que responderam à escala, 55 optaram por responder ao questionário, sendo que as outras 60 professoras não responderam, ou se recusaram a continuar participando da pesquisa.

O questionário é composto por 18 questões divididas em três categorias: questões sobre seus sentimentos em relação à matemática, sobre a matemática, e, questões sobre seu trabalho com a matemática na Educação Infantil. Nesse artigo são apresentadas duas questões que fizeram parte do questionário:

1. Você gosta de matemática? Por quê?

2. Você teve alguma experiência (positiva ou negativa) que marcou sua relação com a matemática? Como foi essa experiência?

Essas questões foram selecionadas por permitirem mais discussões sobre os resultados obtidos na escala de atitudes. Os demais itens do questionário referiam-se a outros construtos investigados pelo pesquisador. 


\section{Participantes}

Participaram desta pesquisa 115 professoras da rede pública de município de Campinas, estado de São Paulo, que trabalham em Centros de Educação Infantil administrados pela Secretaria Municipal de Educação. Todas as participantes eram professoras de Educação Infantil atuando em turmas com idades que variam de zero a cinco anos de idade.

Nenhum participante se identificou como sendo do gênero masculino, sendo assim, ao referir-se ao grupo de docentes, será utilizada a palavra professoras.

Com relação ao tempo de magistério na Educação Infantil, o grupo apresentou perfil mais experiente, sendo, em sua maioria, composto por professoras que têm entre seis e quinze anos de experiência na Educação Infantil.

Além disso, quase todas as participantes possuíam nível superior, bem como tinham outra formação além da Pedagogia, sendo especialização, graduação ou doutorado.

\section{Análise da Escala de Atitudes}

As 115 professoras que responderam à escala de atitudes tiveram seus resultados analisados de acordo com a pontuação obtida por cada uma delas.

Observamos que a média da pontuação obtida pelas 115 professoras na escala de atitudes foi de 61,65 pontos. Observados os resultados individuais, verificou-se que 63 professoras $(54,47 \%$ do total de participantes) apresentaram pontuação abaixo da média, enquanto 52 professoras (45,53\% do total de participantes) apresentaram pontuações que ficaram acima da média. Esses números apontaram que a maioria das participantes apresentou atitudes negativas em relação à matemática.

Gráfico 1 - Pontuação das professoras na Escala de Atitudes

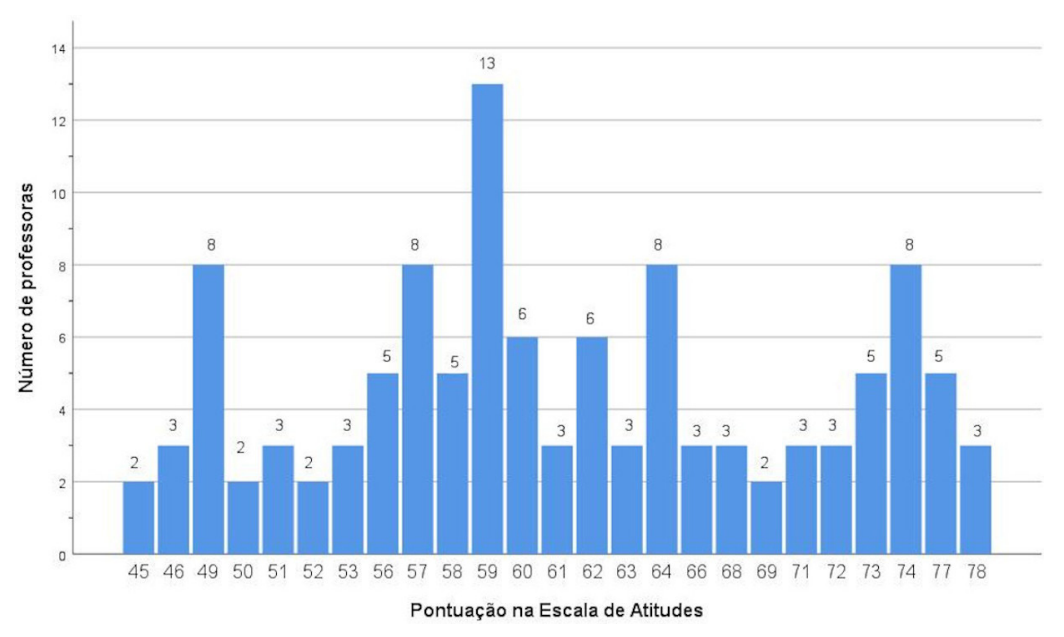

Fonte: Tortora (2019).

Para complementar essa análise, foram feitas algumas comparações estatísticas entre o grupo de professoras que respondeu apenas à escala de atitudes (115 docentes) e o grupo que respondeu à escala de atitudes e ao questionário (55 docentes). Esta comparação é apresentada na tabela 2 e no gráfico 2. 
Tabela 2 - Parte dos dados descritivos referentes a pontuação das professoras na escala de atitudes

\begin{tabular}{|c|c|c|c|c|c|c|}
\hline & Média & Moda & Mediana & Mínimo & Máximo & Desvio padrão \\
\hline $\begin{array}{l}\text { Professoras que responderam } \\
\text { apenas a escala de atitudes }\end{array}$ & 61,6522 & 59,00 & 60,00 & 45,00 & 78,00 & 8,82 \\
\hline $\begin{array}{l}\text { Professoras que responderam } \\
\text { ao questionário e a escala de } \\
\text { atitudes }\end{array}$ & 60,9455 & 58,00 & 59,00 & 45,00 & 78,00 & 9,13 \\
\hline
\end{tabular}

Fonte: Elaborado pelos autores.

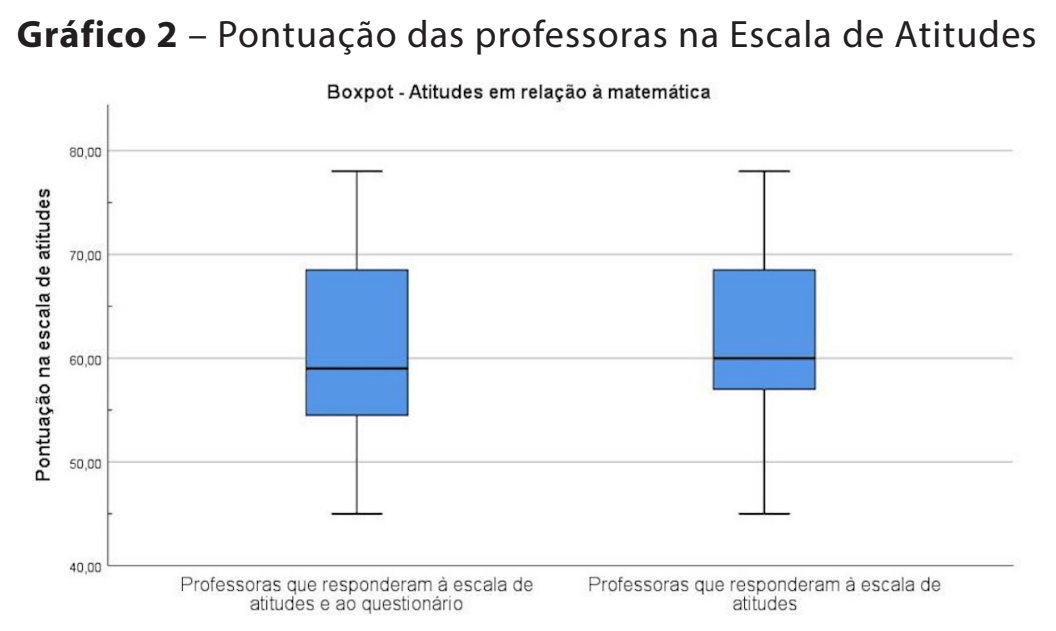

Fonte: Elaborado pelos autores.

Do grupo de professoras que respondeu ao questionário e à escala, observou-se que 28 docentes $(52,72 \%)$ apresentaram pontuações abaixo da média deste grupo (60,94 pontos). Considerando os critérios de análise apontados por Brito (1996), em ambos os grupos de professoras as análises estatísticas apontam que a maioria das docentes apresenta atitudes negativas em relação à matemática.

\section{Análise do Questionário}

Com relação à questão você gosta de matemática? por quê?, considerando os estudos de Brito (1996), as atitudes têm grau de intensidade. As respostas das professoras foram elencadas em três categorias, as quais apresentam os extremos (sim e não) e uma categoria intermediária (gosto intermediário ou indiferente).

As respostas obtidas nos questionários e que fazem referência às atitudes das professoras mostraram um cenário diferente daquele percebido na análise das escalas. A maior parte das professoras que respondeu ao questionário apresentou respostas que se remetem a uma boa relação com a matemática. No total, 36 professoras (aproximadamente $65 \%$ ) assumiram gostar dessa disciplina ao responderem positivamente a questão você gosta de matemática? Além disso, apresentaram argumentos que remetem a uma boa relação com a disciplina desde cedo, como, por exemplo, "sempre gostei" ou "gosto desde quando era aluna". 
Tais resultados corroboram outras pesquisas já realizadas (ARDILES, 2007; MORON, 1998; TRINDADE, 2008), que afirmam que as docentes apresentam atitudes positivas quando questionadas sobre gostar ou não de matemática. Foi bastante comum que as professoras se remetessem à matemática como um conhecimento útil, o que justificaria sua boa relação com os conhecimentos, como nas seguintes respostas: "A matemática está presente em tudo", "Porque acho útil", "Sim, porque nos ajuda na solução de questões da vida cotidiana", "Sim, pois é necessário o tempo todo", "Sim, faz parte do nosso dia a dia", "Sim, a matemática é necessária o tempo todo", "Sim... porque nos ajuda na solução de questões da vida cotidiana", etc.

As professoras também apontaram que as suas boas experiências na escola enquanto alunas foram responsáveis por desenvolver boas atitudes com relação à disciplina, como em: "Porque gosto cálculos desde quando fui aluna", "Sim, porque sempre tive facilidade com números", "Sim, gosto muito de situações problemas envolvendo números", etc.

Outras cinco professoras, aproximadamente $9 \%$ do total, estão na categoria Gosto intermediário ou indiferente. Nesse caso, as professoras disseram ter uma boa relação com a "matemática mais prática" e "do dia a dia", ou disseram ser literalmente indiferentes, dizendo que nunca pensaram em matemática como algo para se gostar ou não, apenas um conhecimento a ser utilizado, dentre tantos outros: "Gosto, quando é utilizada no dia a dia, entretanto a forma como se ensina e se aprende na escola [fundamental e médio] distante do concreto pra mim é complicado e confuso", "Gosto do básico. Não estudei o bastante na área".

Completando o total de respondentes desta questão, 14 professoras responderam não gostar de matemática, aproximadamente $26 \%$ do total. Essas docentes relataram terem tido experiências escolares (enquanto alunas) que contribuíram para esse quadro, como ilustram algumas afirmações: "Não, pois na escola nunca entendi muito bem, sempre ficava de recuperação...", "Não. Não tive incentivo na infância, tive dificuldade para aprender, meus pais só estudaram até $3^{a}$ série. Achava meus professores do fundamental 1 rígidos e tinha medo de perguntar, então permanecia com as dúvidas", "Não, porque nunca entendi direito a matemática", etc. Ao analisarmos a próxima questão: você teve alguma experiência (positiva ou negativa) que marcou sua relação com a matemática? Como foi essa experiência?, as professoras relataram experiências positivas e negativas conforme apresentado no gráfico 3.

Gráfico 3 - Experiências com relação à matemática apontadas pelas professoras nos questionários

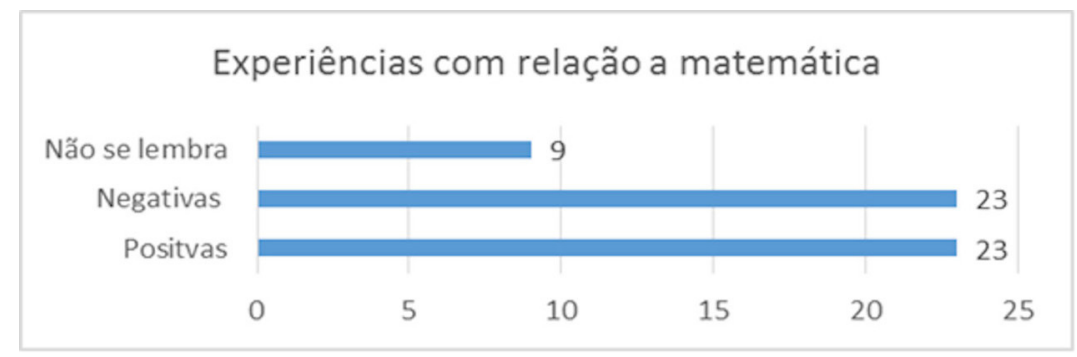

Fonte: Tortora (2019). 
Essa questão apresentou uma diversidade de relatos bastante carregados de sentimentos, e podem explicar um pouco o fato de não gostarem de matemática, como nos casos a seguir:

- "Tive uma professora por dois anos no Ensino Fundamental que fazia a gente ir até a lousa responder alguns cálculos sem aviso prévio e quando não acertávamos, ela nos expunha ao ridículo."

- "Minha professora dava reguada na mesa de quem não acertava suas respostas."

- "Tive uma professora que nos fazia escrever a tabuada na lousa e, quando errávamos ficávamos por último para sair para o recreio. Eu errei algumas vezes e isso me traumatizou muito."

- "Foram experiências ruins: de gritos, borrachas que apagavam tudo, pois não servia contas de cabeça. Professores queriam saber como cheguei ao resultado [correto, por sinal], mas que não serviam nas provas sem que a conta estivesse montada."

Apesar da questão não fazer menção ao contexto escolar, todas as respostas dadas pelas docentes sempre se remeteram à escola, especificamente à figura do professor. As docentes tornaram bastante evidentes os contextos afetivos que desenvolveram tanto um relacionamento positivo, quanto negativo, com a matemática. Brito (1996) salienta que esses argumentos são importantes para conhecer a origem das atitudes para o planejamento de ações para a formação de professores.

Uma observação relevante, com relação aos resultados dos questionários, diz respeito ao fato de algumas professoras, que alegaram gostar de matemática, ao responder a primeira questão (36 docentes), terem tido experiências ruins com a matemática na segunda questão (23 docentes). Isso pode ser explicado pelo fato de que, para algumas professoras, reconhecidas as suas experiências negativas com a matemática, comprometeram-se em mudar sua postura frente à disciplina para não replicar práticas que possam desenvolver atitudes negativas com as crianças. Esses resultados corroboram as análises de Faria, Moro e Brito (2008), que concluíram em seu trabalho que as atitudes em relação à matemática podem sofrer mudanças durante a trajetória profissional docente, ou em sua formação inicial.

\section{Considerações Finais}

Os protocolos analisados apontam que a maioria das professoras participantes apresenta atitudes que tendem a ser negativas em relação à matemática, tanto no grupo que respondeu apenas à escala de atitudes, quanto no grupo que respondeu também ao questionário. Porém, por meio das análises qualitativas, percebe-se que a maioria das professoras que respondeu aos questionários declarou que tem atitudes positivas em relação à matemática.

Numa análise comparativa, esses resultados parecem conflituosos, porém eles devem ser analisados considerando o viés qualitativo da pesquisa, que dá significado a essa divergência. Um percentual próximo da metade das participantes (54,47\% das 115 que responderam apenas à escala de atitudes, e 52,72\% das 55 professoras que responderam à escala e ao questionário) tende a ter atitudes mais negativas em relação à matemática; 
contudo, ao analisarmos o gráfico 1, percebemos que há um número considerável de professoras bastante próximo à média e que, por uma diferença pequena, não foram enquadradas como tendo atitudes positivas em relação à matemática. Nesse sentido, o questionário foi essencial para as análises dos resultados das escalas, visto que, conforme aponta Brito (1996), o resultado obtido na escala de atitudes não é determinístico, uma vez que ele indica tendências negativas ou positivas com relação às atitudes no que se refere à matemática.

Nas análises qualitativas percebeu-se que a maioria das professoras que optou por responder ao questionário apresentou atitudes positivas em relação à matemática e ao trabalho na Educação Infantil. Os argumentos apresentados por essas docentes nos questionários sugerem que o uso da matemática em situações do dia a dia, ou em situações escolares que demandam desafios, tendem a torná-la mais atrativa. Corroborando as pesquisas de Brito (1996), Gonçalez (2000) e Moron (1998), percebemos o quanto essas atitudes influenciam nas intenções pedagógicas perante as práticas das professoras.

Além disso, percebemos que as professoras apontam em seus relatos experiências que se remetem ao contexto escolar, quando questionadas sobre a formação de suas atitudes (apesar de não serem questionadas diretamente sobre suas experiências escolares), o que sugere a importância essencial do professor na formação de atitudes em relação à matemática, corroborando as afirmações de Brito (1996) e Klausmeier (1977).

Para finalizar as análises, outro ponto relevante a ser considerado diz respeito à opção de algumas professoras em não responder ao questionário ou não participar de nenhuma outra etapa da pesquisa. Quando analisados os resultados das escalas de atitudes dessas 60 docentes que optaram por não continuar na pesquisa, ou que não responderam ao questionário, observa-se que 45 delas estão entre as 63 professoras que tendem ter atitudes negativas em relação à matemática.

Não se sabe ao certo o que motivou a não continuidade dessas professoras na pesquisa, contudo, esse cenário sugere que as docentes com atitudes negativas sejam convidadas a expressar seus motivos para não continuar participando da pesquisa. Essa investigação torna-se relevante observando que, para além da não participação das professoras, algumas equipes gestoras de Centros de Educação Infantil não concederam espaço para o pesquisador dialogar com os professores sobre a temática, alegando não ter tempo, ou que seus professores optaram pela não participação em pesquisas externas. Faria, Moro e Brito (2008) apontam a importância das pesquisas atuais em verificar as crenças e atitudes das professoras, mas a opção por não participar das pesquisas, muitas vezes, impossibilita o trabalho de qualquer pesquisador.

Talvez os investigadores envolvidos nesse estudo estejam diante de uma das principais dificuldades a serem enfrentadas: considerando-se que a parceria com o pesquisador poderia enriquecer a prática das docentes, como convidar as professoras - e equipes gestoras - com atitudes negativas, e que se recusaram a participar da pesquisa, a encontrarem-se em uma prática em que os seus conhecimentos (ou de outros agentes externos à instituição em que trabalha) possam auxiliar na sua práxis?

Reconhecemos que esta questão não poderá ser respondida no atual momento com os dados que foram construídos até o momento, visto que demanda aprofundamento teórico e investigativo. Porém, temos indicativos de que é necessário um projeto que envolva a gestão de pessoas, na qual as professoras que aceitaram participar da pesquisa 
tornam-se fundamentais: são elas as multiplicadoras de suas práticas e experiências. Estas últimas docentes apresentam atitudes frente à pesquisa que podem ser inspiração para as professoras que optaram por não participar, bem como podem ajudá-las a dialogar sobre o trabalho com matemática na Educação Infantil.

Esse artigo mostra a importância de um planejamento de ações formativas, sugerindo, como ponto de partida, conhecer as atitudes dos professores em relação à matemática. Esse tipo de formação continuada ou inicial permitiria instigar a superação de atitudes negativas e compartilhar atitudes positivas. Conhecidos esses parâmetros, é possível trabalhar com outras tarefas da prática do professor nas quais as atitudes têm grande influência, como o planejamento, as interações nas atividades com as crianças, a avaliação de aprendizagens, a seleção de tempos e espaços educativos, entre outras.

\section{Referências}

AIKEN JR., L. R. Attitudes toward mathematics. Review of Educational Research, Washington, v. 40, n. 4, p. 551-596, 1970. DOI: https://doi.org/fs9435.

AIKEN JR., L. R.; DREGER, R. M. The effect of attitudes on performance in mathematics. Journal of Educational Psychology, Arlington, v. 52, n. 1, p. 19-24, 1961. DOI: https://doi.org/10.1037/ h0041309.

ARDILES, R. N. Um estudo sobre as concepções, crenças e atitudes dos professores em relação a matemática. 2007. 237 f. Dissertação (Mestrado em Educação) - Faculdade de Educação, Universidade Estadual de Campinas, Campinas, 2007. Disponível em: http://repositorio.unicamp. br/jspui/handle/REPOSIP/251466. Acesso em: 18 out. 2020.

BRASIL. Ministério da Educação. Diretrizes curriculares nacionais para a educação infantil. Brasília: MEC, 2010. Disponível em: https://cutt.ly/NgmqxFD. Acesso em: 25 out. 2020.

BRASIL. Ministério da Educação. Base nacional comum curricular. Brasília: MEC, 2018. Disponível em: http://basenacionalcomum.mec.gov.br/. Acesso em: 25 out. 2020.

BRITO, M. R. F. Um estudo sobre as atitudes em relação à matemática em estudantes de $1^{\circ}$ e $2^{\circ}$ graus. 1996. 383 f. Tese (Livre Docência) - Faculdade de Educação, Universidade Estadual de Campinas, Campinas, 1996. Disponível em: http://repositorio.unicamp.br/jspui/handle/REPOSIP/251566. Acesso em: 18 out. 2020.

COUTINHO, M. C. Relações entre crenças de autoeficácia, atitudes, atribuição de sucesso e fracasso em matemática: um estudo com alunos em transição do $5^{\circ}$ para o $6^{\circ}$ ano. 2020. $257 \mathrm{f}$. Dissertação (Mestrado em Educação para a Ciência) - Faculdade de Ciências, Universidade Estadual Paulista, Bauru, 2020. Disponível em: https://repositorio.unesp.br/handle/11449/192285. Acesso em: 25 out. 2020.

DE CORTE, E. Fostering cognitive growth: a perspective from research on mathematics learning and instruction. Educational Psychologist, Hillsdale,v. 30, n. 1, p. 37-46, 1995. DOI: https://doi.org/ bk48xn.

FARIA, P. C.; MORO, M. L. F.; BRITO, M. R. F. Atitudes de professores e futuros professores em relação à matemática. Estudos de Psicologia, Natal, v. 13, n. 3, p. 257-265, 1998. Disponível em: https://www.scielo.br/pdf/epsic/v13n3/a08v13n3.pdf. Acesso em: 25 out. 2020.

FERREIRA, A. L. Pesquisa quantitativa e qualitativa: perspectivas para o campo da educação. Mosaico, Goiânia, v. 8, n. 2, p. 173-182, 2015. 
FREITAS, A. L. P.; RODRIGUES, S. G. A avaliação da confiabilidade de confiabilidade de questionários: uma análise utilizando o coeficiente alfa de Cronbach. In: SIMPÓSIO DE ENGENHARIA DE PRODUÇÃO, 12., 2005, Bauru. Anais [...]. Disponível em: https://cutt.ly/ ZgmqDho. Acesso em: 10 maio 2020.

GONÇALEZ, M. H. C. C. Atitudes (des)favoráveis com relação à matemática. 1995. 147 f. Dissertação (Mestrado em Psicologia Educacional) - Faculdade de Educação, Universidade Estadual de Campinas, Campinas, 1995. Disponível em: http://repositorio.unicamp.br/jspui/handle/ REPOSIP/251628. Acesso em: 10 maio 2020.

GONÇALEZ, M. H. C. C. Relações entre a família, o gênero, o desempenho, a confiança e as atitudes em relação à matemática. 2000. 171 f. Tese (Doutora em Educação) - Universidade Estadual de Campinas, Campinas, 2000. Disponível em: http://repositorio.unicamp.br/handle/ REPOSIP/251473. Acesso em: 10 maio 2020.

JUSTULIN, A. M. Um estudo sobre as relações entre atitudes, gênero e desempenho de alunos do ensino médio em atividades envolvendo frações. 2009. 250 f. Dissertação (Mestrado em Educação para a Ciência) - Faculdade de Ciências, Universidade Estadual Paulista, Bauru, 2009. Disponível em: https://repositorio.unesp.br/handle/11449/90893. Acesso em: 25 out. 2020.

KLAUSMEIER, H. J. Manual de psicologia educacional: aprendizagem e capacidades humanas. São Paulo: Harper \& Row, 1977.

MORAES, M. S.; PIROLA, N. A. Atitudes positivas em relação à matemática. In: BRASIL. Ministério da Educação. Pacto nacional pela alfabetização na idade certa: alfabetização matemática na perspectiva do letramento. Brasília: MEC, 2015. p. 62-72.

MORON, C. F. Um estudo exploratório sobre as concepções e as atitudes dos professores de educação infantil em relação à matemática. 1998. 133 f. Dissertação (Mestrado em Psicologia Educacional) Faculdade de Educação, Universidade Estadual de Campinas, Campinas, 1998.

SANDER, G. P. Pró-Letramento: um estudo sobre a resolução de problemas e as atitudes em relação à matemática apresentadas por professores do primeiro ciclo do ensino fundamental. 2014. 214 f. Dissertação (Mestrado em Educação para a Ciência) - Faculdade de Ciências, Universidade Estadual Paulista, Bauru, 2014. Disponível em: https://repositorio.unesp.br/handle/11449/154653. Acesso em: 25 out. 2020.

SANTANA, R. R. F. Um estudo sobre as relações entre o desenvolvimento do pensamento algébrico, as crenças de autoeficácia, as atitudes e o conhecimento especializado de professores pre-service e in-service. 2019. 321 f. Dissertação (Mestrado em Educação para a Ciência) - Faculdade de Ciências, Universidade Estadual Paulista, Bauru, 2019. Disponível em: https://repositorio.unesp.br/ handle/11449/183663. Acesso em: 25 out. 2020.

TORTORA, E. O lugar da matemática na educação infantil: um estudo sobre as atitudes e crenças de autoeficácia das professoras no trabalho com as crianças. 2019. 222 f. Tese (Doutorado em Educação para a Ciência) - Faculdade de Ciências, Universidade Estadual Paulista, Bauru, 2019. Disponível em: https://repositorio.unesp.br/handle/11449/191442. Acesso em: 25 out. 2020.

TRINDADE, A. F. P. Investigações matemáticas e resolução de problemas: que fronteiras? 2008. $174 \mathrm{f}$. Dissertação (Mestrado em Educação) - Universidade Federal do Paraná, Curitiba, 2008. Disponível em: http://www.ppge.ufpr.br/teses/M08_trindade.PDF. Acesso em: 25 out. 2020

VENDRAMINI, C. M. M. Implicações das atitudes e das habilidades matemáticas na aprendizagem dos conceitos de estatística. 2000. 252 f. Tese (Doutorado em Educação) - Faculdade de Educação, Universidade Estadual de Campinas, Campinas, 2000. Disponível em: http://repositorio.unicamp. br/jspui/handle/REPOSIP/251835. Acesso em: 25 out. 2020.

WIGGERS, V. Estratégias metodológicas pertinentes à sistematização do trabalho cotidiano na creche e na pré-escola. In: FLÔR, D. C.; DURLI, Z. (org.). Educação infantil e formação de professores. Florianópolis: Editora da UFSC, 2012. p. 97-114. 